\title{
Padrão de deposição de sementes e sobrevivência de sementes e plântulas de duas espécies de Myrtaceae na Mata Atlântica
}

\begin{abstract}
MARCO A. PIZO ${ }^{1}$
(recebido: 2 de maio de 2002; aceito: 4 de julho de 2003)

ABSTRACT - (Seed deposition pattern and survival of seeds and seedlings of two Atlantic Forest Myrtaceae species). Although birds and monkeys frequently eat fruits of the same plant species, these animals may differ in the quality of seed dispersal they promote. The seed deposition patterns produced by birds and monkeys, for example, are likely different; while birds often regurgitate isolated seeds, monkeys defecate seeds in groups. In this paper the survivorship of seeds and seedlings of two Myrtaceae species occurring in the Brazilian Atlantic Forest (Gomidesia anacardiifolia and Marlierea obscura), experimentally arranged in the field in order to simulate the deposition patterns produced by birds and monkeys, was investigated. After six months of monitoring, the survivorship of seeds and seedlings considered separately between the isolated and grouped treatments differed, but the amount and direction of differences depended on plant species. When both phases (seeds and seedlings) are analyzed together, results indicate that for both plant species tested the deposition of isolated seeds provided a better balance between number of dispersed seeds and number of established seedlings, suggesting that, in comparison with monkeys, birds may optimize the reproductive effort of G. anacardiifolia and M. obscura.
\end{abstract}

Key words - Atlantic Forest, Myrtaceae, seed dispersal, seed predation

RESUMO - (Padrão de deposição de sementes e sobrevivência de sementes e plântulas de duas espécies de Myrtaceae na Mata Atlântica). Embora aves e macacos freqüentemente se alimentem dos mesmos frutos, a qualidade da dispersão de sementes produzida por estes animais pode diferir em vários aspectos. Um desses aspectos é o padrão de deposição de sementes ou o modo como as sementes são depositadas no ambiente; aves tendem a depositar sementes isoladas enquanto os macacos as depositam agrupadas. Neste trabalho investigou-se, para duas espécies de Myrtaceae da Mata Atlântica (Gomidesia anacardiifolia e Marlierea obscura) cujos frutos possuem características ornitocóricas, mas que na natureza são comidos por aves e macacos, a sobrevivência de sementes e plântulas experimentalmente arranjadas de modo a simular os padrões de deposição de sementes produzidos por estes dispersores. Ao final de seis meses de acompanhamento, os resultados indicaram diferenças entre os tratamentos isolado e agrupado na sobrevivência de sementes e plântulas consideradas separadamente. A magnitude e direção de tais diferenças, entretanto, variaram interespecificamente. Ao analisar as duas fases (semente e plântula) em conjunto, concluiu-se que, para ambas as espécies de plantas, o padrão de deposição isolado deve produzir um balanço entre número de sementes dispersadas e número de plântulas estabelecidas mais favorável que o padrão agrupado. Isto sugere que, em comparação com macacos, as aves otimizam o esforço reprodutivo das plantas pesquisadas.

Palavras-chave - dispersão de sementes, floresta Atlântica, Myrtaceae, predação de sementes

\section{Introdução}

Recentemente a idéia de que as síndromes de dispersão (sensu van der Pijl 1982) associadas a frutos carnosos foram evolutivamente moldadas pelos agentes dispersores tem sido questionada, não somente porque várias das características morfológicas que definem estas síndromes parecem ser filogeneticamente determinadas (Herrera 1992, Janson 1992, Jordano 1995), mas também porque freqüentemente observamos um determinado agente dispersor ingerindo frutos cujas características os colocam em uma síndrome associada a outro grupo de dispersores. Macacos, por exemplo,

1. Universidade Estadual Paulista, Instituto de Biociências, Departamento de Botânica, Caixa Postal 199, 13506-900 Rio Claro, São Paulo, Brasil. pizo@rc.unesp.br. freqüentemente comem frutos ornitocóricos (sensu van der Pijl 1982; Pizo 2002).

Entretanto, ingerir um fruto não é sinônimo de dispersar suas sementes de maneira eficiente. A eficiência de um determinado animal frugívoro como dispersor depende também de aspectos relacionados ao padrão de deposição das sementes que esse animal produz, ou seja, como e onde as sementes ingeridas são depositadas (Schupp 1993). Em relação a estes aspectos, aves e macacos podem diferir consideravelmente (Clark et al. 2001). Enquanto os macacos defecam as sementes em grupos ao se deslocarem pela floresta ou sob seus dormitórios (Julliot 1997, Izar 1999), as aves freqüentemente as regurgitam uma a uma ao se deslocarem pelo ambiente (Levey 1987). Assim os macacos produzem um espectro de deposição mais agregado que as aves, o que pode levar 
a diferenças na sobrevivência das sementes e plântulas resultantes. Sementes agrupadas podem sofrer maiores taxas de predação do que sementes isoladas (Willson \& Whelan 1990, Hammond 1995), embora este não seja um padrão universal (Forget \& Milleron 1991, Notman et al. 1996, Pizo \& Simão 2001). As plântulas produzidas a partir de sementes agrupadas, por sua vez, estão sujeitas a maior competição intraespecífica que plântulas isoladas (Howe 1989, Loiselle 1990, Pizo \& Simão 2001).

Assim, o objetivo deste trabalho foi investigar, para duas espécies de Myrtaceae (Gomidesia anacardiifolia (Gardn.) O. Berg e Marlierea obscura O. Berg) cujos frutos possuem características ornitocóricas (pequeno tamanho, coloração vermelha ou preta), mas que na natureza são comidos por aves e macacos, a sobrevivência de sementes e plântulas experimentalmente arranjadas de modo a simular os padrões de deposição de sementes produzidos por estes dispersores. Uma vez que tais frutos possuem características ornitocóricas, procurou-se investigar a hipótese de que sementes e plântulas isoladas, que simulam a deposição produzida por aves, teriam maiores chances de sobrevivência do que sementes e plântulas agrupadas, que simulam a deposição produzida por macacos.

\section{Material e métodos}

Área de estudo e espécies estudadas - O estudo foi realizado durante visitas mensais realizadas de maio de 2001 a janeiro de 2002 ao Parque Estadual Intervales (SMA 2001), mais especificamente à Base de Pesquisa Saibadela $\left(24^{\circ} 14^{\prime} \mathrm{S}\right.$, $48^{\circ} 04^{\prime}$ W) localizada no município de Sete Barras, sul do estado de São Paulo. A Base Saibadela situa-se a 70 m s.n.m. e está sujeita a uma precipitação anual média de aproximadamente $4.000 \mathrm{~mm}$, com chuvas bem distribuídas ao longo do ano (nenhum mês recebe menos de $100 \mathrm{~mm}$ de chuva). Pode-se distinguir uma estação quente e úmida de setembro a março, quando a temperatura pode atingir $42^{\circ} \mathrm{C}$ (média \pm desvio padrão para o período 1994-1996: 25,7 \pm $2,8^{\circ} \mathrm{C}$ ), e uma estação mais seca e fria que se estende de abril a agosto, período em que a temperatura eventualmente chega abaixo de $10^{\circ} \mathrm{C}\left(20,8 \pm 2,5^{\circ} \mathrm{C}\right)$.

A vegetação na Base Saibadela, classificada como Floresta Atlântica Ombrófila Densa (sensu Joly et al. 1991) encontra-se em excelente estado de conservação. Trata-se em sua maior parte de floresta primária, com sub-bosque aberto e copa situada a 25-30 m (Almeida-Scabbia 1996). A família Myrtaceae é a mais numerosa em espécies ( $>40$ espécies representando 10 gêneros) e em número de indivíduos com diâmetro à altura do peito (DAP) $>5 \mathrm{~cm}$
(Almeida-Scabbia 1996). Dentre as mirtáceas, Marlierea obscura é das mais abundantes na área de estudo $(23,1$ indivíduos [DAP $>5 \mathrm{~cm}$ ].ha ${ }^{-1}$ ), enquanto Gomidesia anacardiifolia ocorre em densidade bem menor $(1,9$ indivíduos.ha ${ }^{-1}$; Almeida-Scabbia 1996). Ambas produzem pequenos frutos carnosos (diâmetro $\leq 15 \mathrm{~mm}$ ), vermelhos quando maduros em $G$. anacardiffolia e pretos em M. obscura, comidos por aves e macacos na área de estudo (Petroni 2000, M.A. Pizo, dados não publicados). Cada fruto possui 1-2 sementes cujos comprimentos, larguras e respectivos desvios padrões são $9,1 \pm 0,6 \mathrm{~mm}$ e $7,1 \pm 0,5 \mathrm{~mm}$ para M. obscura e $8,9 \pm 0,6 \mathrm{~mm}$ e $8,1 \pm 0,8 \mathrm{~mm}$ para G. ancardiifolia $(\mathrm{N}=10$ para todas as medidas; M.A. Pizo, dados não publicados). Os períodos de frutificação de ambas as espécies sobrepõem-se, estendendo-se de maio a setembro em G. anacardiifolia e julho a agosto em Marlierea obscura.

A área de estudo é cortada por várias trilhas estreitas (1-2 m) que alteraram minimamente a vegetação circundante. Essas trilhas foram usadas para o estabelecimento das estações experimentais descritas abaixo.

Métodos - Para testar o efeito do padrão de deposição sobre a sobrevivência de sementes e plântulas de Gomidesia anacardiifolia e Marlierea obscura (a partir daqui tratadas apenas pelo gênero) sementes das duas espécies, aparentemente saudáveis, sem sinais de ataque por fungos ou outros predadores, foram coletadas diretamente da copa das árvores ou de frutos recém-caídos e designadas a um dos seguintes tratamentos: sementes agrupadas e sementes isoladas. No tratamento "sementes agrupadas", grupos de cinco sementes foram colocados em pontos no chão da floresta (denominados estações experimentais) estabelecidos a 1-2 m das trilhas que cortam a área de estudo. Tais estações experimentais estavam espaçadas por pelo menos $50 \mathrm{~m}$ umas das outras, em pontos da floresta distantes pelo menos $10 \mathrm{~m}$ de qualquer clareira. Em cada grupo as sementes foram dispostas em contato umas com as outras, simulando assim o padrão de deposição encontrado nas fezes de macacos (Izar 1999). No tratamento "sementes isoladas", uma única semente foi colocada em cada estação localizada a 3-6 m das estações que receberam as sementes do tratamento anterior. A semente isolada simula o padrão de deposição produzido pelas aves ao regurgitarem as sementes uma a uma. A disponibilidade de sementes determinou o número de estações usadas para cada espécie, 22 para cada tratamento em Gomidesia e 39 para cada tratamento em Marlierea. A localização de cada grupo de semente ou semente isolada foi marcada por bandeirolas coloridas. Ambos os tratamentos foram testados concomitantemente, na época de frutificação de cada espécie. O número de sementes e/ou plântulas sobreviventes, ou seja, aquelas presentes na estação e aparentemente intactas, foi registrado mensalmente por seis meses a partir de junho de 2001 para Gomidesia e julho do mesmo ano para Marlierea. Considerou-se predada a semente não encontrada em uma área de $30 \mathrm{~cm}$ de raio a partir de sua posição original, ou aquela encontrada, porém parcialmente 
comida. A alta abundância e riqueza de roedores na área de estudo (Vieira 1999), associada à infreqüência de outros mamíferos e aves granívoras potenciais predadores de sementes (M.A. Pizo, dados não publicados) e à não observação de invertebrados (larvas ou adultos) alimentando-se das sementes, fazem dos roedores os mais prováveis predadores das sementes usadas neste estudo. Embora os roedores possam eventualmente atuar como dispersores secundários de algumas das sementes que removem para seus ninhos, isso ocorre principalmente para sementes maiores e mais rígidas do que as usadas neste estudo (Briani et al. 2001).

Análises estatísticas - Neste estudo foi considerado um dos componentes da predação, a taxa de encontro ("encounter rate" sensu Hulme \& Hunt 1999), que refere-se à probabilidade de que uma estação experimental tenha ao menos uma semente predada. Diferenças entre os tratamentos na taxa de encontro foram testadas usando-se o teste de quiquadrado aplicado ao número de estações que tiveram ao menos uma semente removida e estações que não sofreram remoção. A remoção das sementes foi verificada ao final do primeiro mês, pois a partir do segundo mês todas as sementes de ambas as espécies já havia germinado e foram então consideradas plântulas.

Para comparar os tratamentos em relação ao número de estações que não sofreram qualquer mortalidade (de sementes ou plântulas) até o final do estudo, foi usado o teste exato de Fischer (Zar 1984).

\section{Resultados}

O número de estações com sementes de Gomidesia encontradas pelos roedores não diferiu entre os tratamentos "sementes isoladas" e "sementes agrupadas" (13 e 18 estações, respectivamente; $\chi^{2}=$ $1,75, \mathrm{P}=0,18, \mathrm{~N}=22$ ). Para Marlierea, entretanto, os roedores encontraram quase o dobro de estações com sementes agrupadas ( 14 e 27 estações; $\chi^{2}=7,405, \mathrm{P}=$ $0,006, \mathrm{~N}=39)$. No total $59,0 \%(\mathrm{~N}=22)$ das sementes isoladas e $55,5 \%(\mathrm{~N}=110)$ das sementes agrupadas de Gomidesia foram removidas. Para Marlierea, estas porcentagens foram menores: $35,8 \%(\mathrm{~N}=39)$ e $51,3 \%$ $(\mathrm{N}=195)$, respectivamente.

Sementes isoladas e agrupadas de Gomidesia produziram oito e 30 plântulas (em oito e 13 estações), respectivamente. Destas, $62,5 \%$ das plântulas isoladas e 73,3\% das plântulas agrupadas estavam vivas ao final do período de observação. Para Marlierea foram produzidas 16 plântulas (em 16 estações) a partir de sementes isoladas e 67 plântulas agrupadas (em 25 estações; uma estação acidentalmente pisoteada). Ao final das observações, $71,4 \%$ das plântulas isoladas e
54,7\% das plântulas agrupadas de Marlierea estavam vivas.

Considerando as fases de semente e plântula em conjunto, observa-se que a sobrevivência de sementes e plântulas de Marlierea foi, ao longo do estudo, consistentemente maior no tratamento "sementes isoladas". O mesmo não se verificou para Gomidesia (figura 1). Apenas cinco estações (22,7\%) do tratamento "sementes isoladas" de Gomidesia não sofreram mortalidade, isto é, ao final do estudo tinham o número de plântulas correspondente ao número original de sementes depositadas na estação. No tratamento "sementes agrupadas", todas as estações sofreram algum tipo de mortalidade, resultando em uma diferença estatisticamente significativa na comparação com o tratamento anterior $(\mathrm{P}=0,05)$. Para Marlierea, 11 estações $(28,2 \%)$ do tratamento "sementes isoladas" não sofreram mortalidade, enquanto todas as estações do tratamento "sementes agrupadas" perderam sementes e/ou plântulas ( $\mathrm{P}<0,001)$. Para ambas as espécies, a maioria das estações do tratamento "sementes agrupadas" chegaram ao final do estudo com no máximo duas plântulas vivas (figura 2).

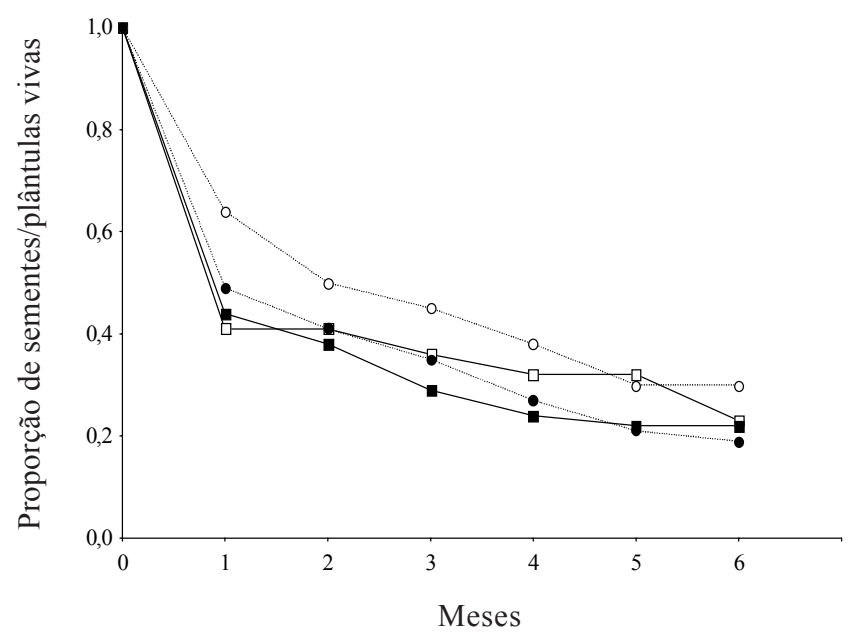

Figura 1. Curvas de sobrevivência de sementes (até o primeiro mês) e plântulas isoladas e agrupadas de Gomidesia anacardiifolia e Marlierea obscura no Parque Estadual Intervales. - $\square-$ Gomidesia - isolada $(\mathrm{N}=22)$; - - - Gomidesia - agrupada $(\mathrm{N}=110)$; --O-Marlierea - isolada $(\mathrm{N}=39)$; - - - Marilierea - agrupada $(\mathrm{N}=195)$.

Figure 1. Survivorship curves for seeds (up to first month), and isolated and clumped seedlings of Gomidesia anacardiifolia and Marlierea obscura at Parque Estadual Intervales. $-\square-$ Gomidesia - isolated $(\mathrm{N}=22) ;-\square-$ Gomidesia - clumped ( $\mathrm{N}=110)$; - - O-Marlierea - isolated $(\mathrm{N}=39)$; - $\bullet$ - Marilierea - clumped ( $\mathrm{N}=195)$. 


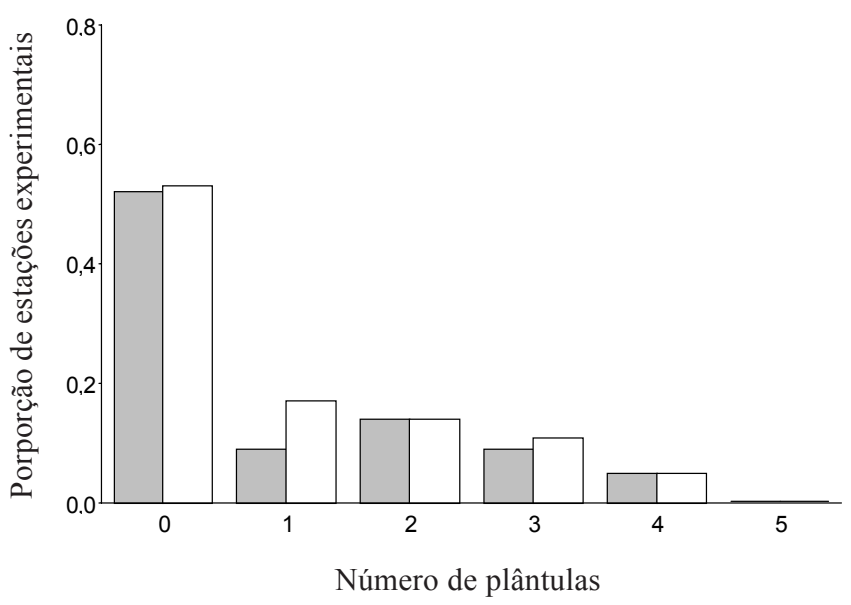

Figura 2. Distribuição de freqüências de plântulas agrupadas de Gomidesia anacardiifolia (barras cinza; $\mathrm{N}=22$ estações experimentais) e Marlierea obscura (barras claras; $\mathrm{N}=36$ estações experimentais) presentes nas estações experimentais ao final do estudo, seis meses após as sementes serem colocadas nas estações experimentais.

Figure 2. Frequency distribution of clumped seedlings of Gomidesia anacardiifolia (grey bars; $\mathrm{N}=22$ experimental stations) and Marlierea obscura (opened bars; $\mathrm{N}=36$ experimental stations) in the experimental stations at the end of the study, six months after seeds were set at experimental stations.

A figura 3 resume os resultados obtidos reunindo as probabilidades de transição de uma fase a outra, ou seja, de semente a plântula recém emergida e desta a plântula com seis meses de idade. Apresenta também a probabilidade cumulativa de uma semente produzir uma plântula viva ao final do estudo. Fica claro nesta figura (veja também figura 1) que a maior mortalidade ocorreu na fase de semente (em média, 65,2\%, considerando ambos os tratamentos e espécies em conjunto) se comparada com a mortalidade das plântulas (em média, $12,0 \%)$. A mortalidade na fase de semente deveu-se principalmente à remoção, e provável predação, por roedores (figura 3). É interessante notar que, embora a remoção por roedores das sementes de Gomidesia tenha sido maior para as sementes isoladas, outras causas de mortalidade (fungos?) agiram mais intensamente sobre as sementes agrupadas, resultando, como em Marlierea, em maior sobrevivência das sementes isoladas.

Comparando ambas as espécies testadas, nota-se que embora a probabilidade de sementes originarem plântulas recém emergidas tenha sido maior no tratamento "sementes isoladas" para ambas as espécies, apenas para Marlierea esta tendência se mantém na transição plântulas recém emergida-plântula com seis meses (figura 3). Apesar disso, a probabilidade cumulativa de uma semente resultar em uma plântula com seis meses foi, para ambas as espécies, maior no tratamento "sementes isoladas" quando comparado ao tratamento "sementes agrupadas". A diferença entre os dois tratamentos foi mais acentuada para Marlierea (10\%) que para Gomidesia (3\%).

\section{Discussão}

Estudos que comparam a sobrevivência de sementes agregadas e isoladas têm obtido resultados contrastantes. Enquanto alguns indicam que sementes isoladas estão menos sujeitas à predação que sementes agrupadas (Hammond 1995), outros não encontraram qualquer diferença entre estes dois tratamentos (Chapman 1989, Forget \& Milleron 1991, Notman et al. 1996, Pizo \& Simão 2001). Os resultados obtidos para as sementes de Gomidesia e Malierea refletem esta divergência de resultados. Enquanto sementes isoladas e agrupadas de Gomidesia foram encontradas pelos roedores e predadas em proporções semelhantes, as sementes isoladas de Marlierea foram encontradas em menor proporção e tenderam a apresentar maior sobrevivência que as sementes agrupadas. Alguns estudos mostraram que a probabilidade de encontro de um determinado grupo de sementes por roedores está positivamente relacionada ao número de sementes presentes (Willson \& Whelan 1990, Blate et al. 1998), como parece ser o caso de Marlierea no presente estudo. Entretanto, como indicam os trabalhos acima citados nos quais não foram encontradas diferenças na remoção de sementes isoladas e agrupadas, esta mesma relação não é válida para todas as espécies de roedores e/ou sementes. Assim, as diferenças encontradas entre Gomidesia e Marlierea no que se refere à remoção por roedores podem estar relacionadas a características intrínsecas às sementes que afetam de modo diferente para as duas espécies sua atração e palatabilidade aos roedores (Kelrick et al. 1986)

Como as causas de mortalidade de plântulas não foram identificadas, não é possível avaliar a incidência de fatores dependentes, como competição intraespecífica, e independentes, como herbivoria, da densidade de plântulas. Houve, entretanto, uma tendência para plântulas isoladas de Marlierea sobreviverem em maior proporção do que plântulas agrupadas, enquanto o inverso foi observado para Gomidesia (figura 1). Uma vez que a mortalidade das plântulas é lenta e ocorre em intervalos de tempo que vão além dos seis meses investigados neste estudo 
Gomidesia anacardiifolia

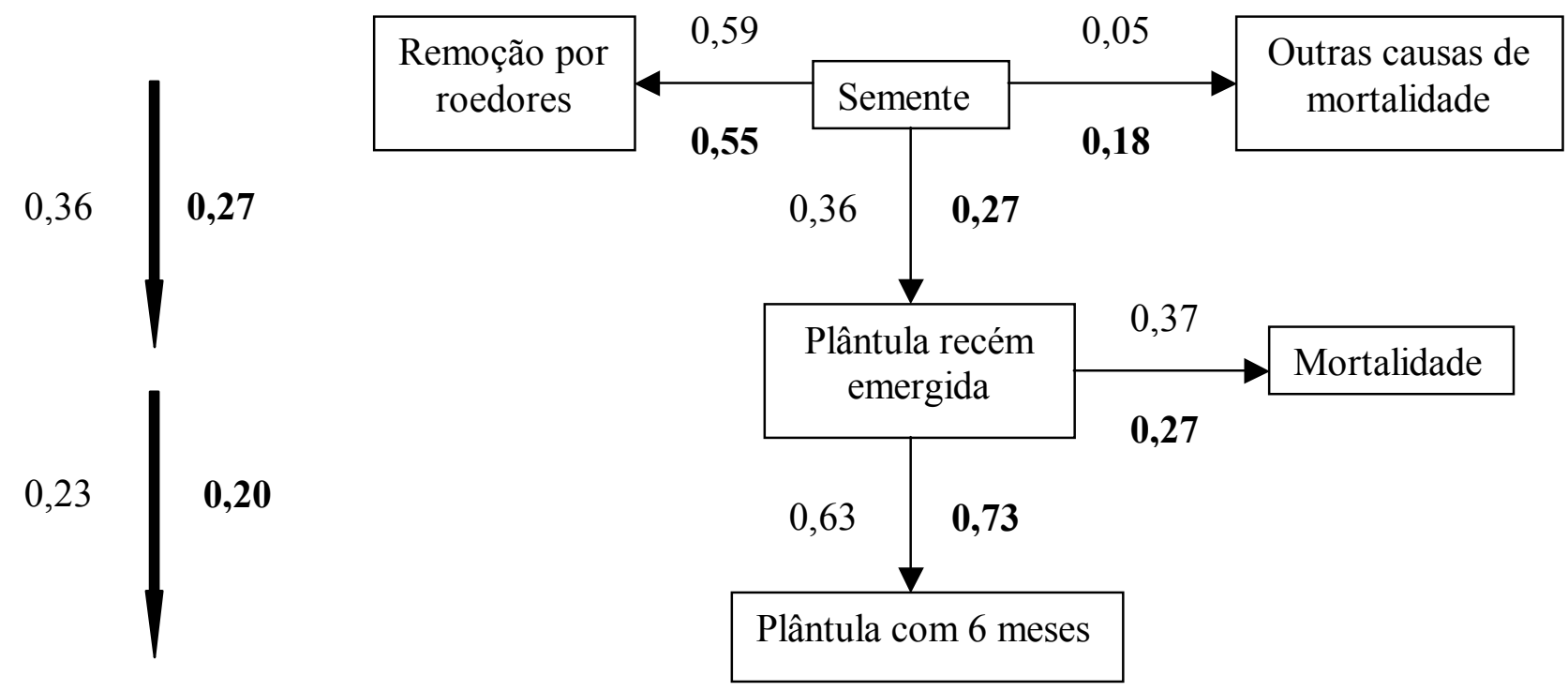

Marlierea obscura

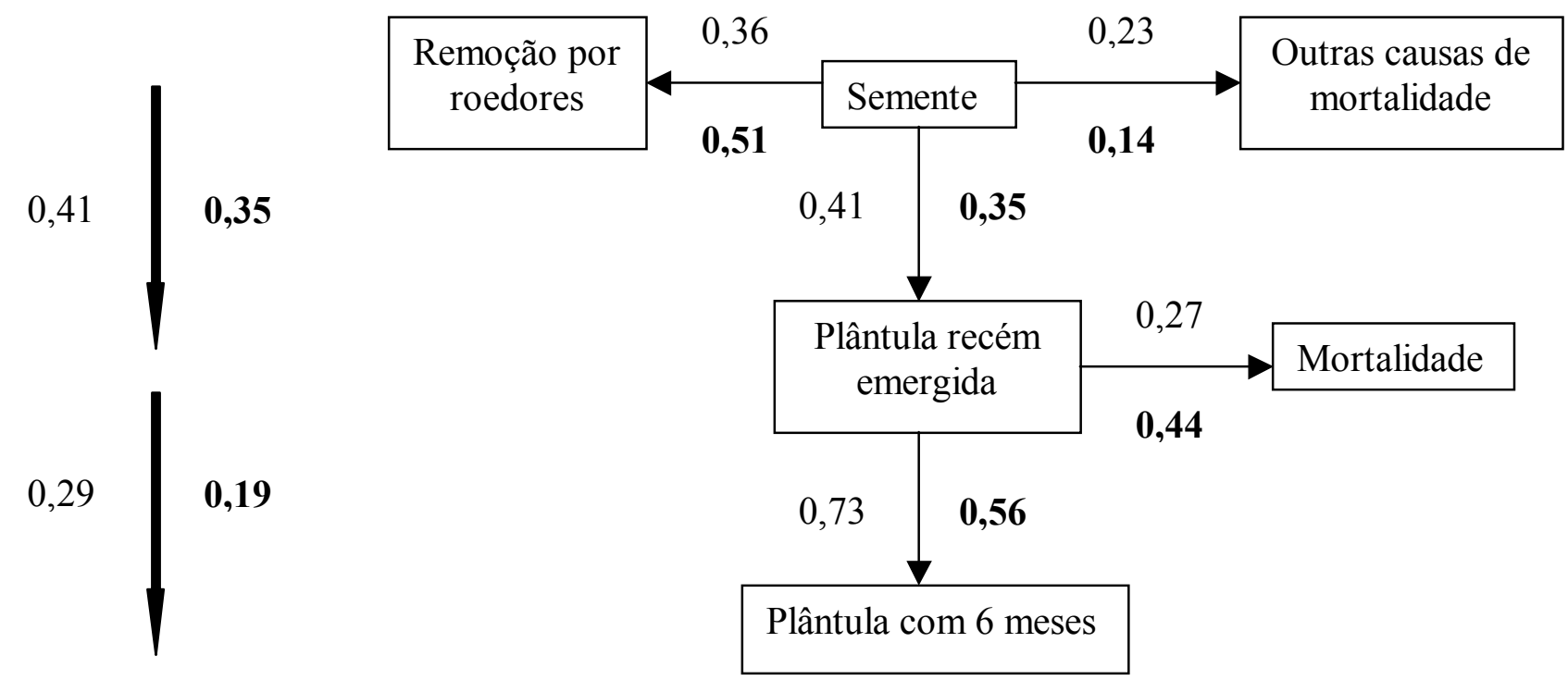

Figura 3. Probabilidades de transição e de mortalidade (dado em proporção) de sementes e plântulas de Gomidesia anacardiifolia e Marlierea obscura nos tratamentos isolado e agrupado (valores em negrito). Os valores junto às setas mais grossas à esquerda referem-se à probabilidade cumulativa. Os números iniciais de sementes para os tratamentos isolado e agrupado para Gomidesia são 22 e 110, e para Marlierea, 39 e 195, respectivamente.

Figure 3. Transition and mortality probabilities (given in proportions) of seeds and seedlings of Gomidesia anacardiifolia and Marlierea obscura in isolated and clumped (boldface values) treatments. Proportions indicated along the vertical arrows on the left refer to cumulative probabilities. The initial number of seeds in isolated and clumped cohorts are, respectively, 22 and 110 for Gomidesia, and 39 and 195 for Marlierea. 
(Chapman 1989), é possível que as diferenças na sobrevivência de plântulas agregadas e isoladas se mantenham ou desapareçam ao longo do tempo. Um estudo sobre a distribuição espacial dos indivíduos adultos de ambas as espécies seria esclarecedor a este respeito. Caso as diferenças interespecíficas aqui reveladas se mantivessem, estudo de tal natureza revelaria que a distância para o indivíduo coespecífco mais próximo é menor em Gomidesia que em Marlierea.

Apesar de Gomidesia e Marlierea apresentarem resultados contrastantes no que se refere à sobrevivência de sementes e plântulas separadamente, quando estas duas fases são analisadas em conjunto nota-se que o padrão de deposição isolado propicia a ambas as espécies, porém de maneira mais evidente para Marlierea, um balanço entre número de sementes dispersadas e número de plântulas estabelecidas mais favorável que o padrão agrupado. Em outras palavras, o padrão de deposição agrupado produzido pelos macacos parece representar um maior "desperdício" de sementes do que o padrão isolado produzido pelas aves (Howe 1980). Para Marlierea, foram necessárias 5,6 sementes agrupadas e 3,9 sementes isoladas para produzir uma plântula viva ao final do estudo. Para Gomidesia estas proporções seguiram a mesma tendência, porém foram mais semelhantes entre si: 5,8 e 5,5 sementes/plântula, respectivamente. Ambos os grupos de dispersores podem ainda diferir em relação a outros aspectos relacionados à eficiência na dispersão de sementes (sensu Schupp 1993) que não foram investigados nesse estudo como, por exemplo, a quantidade de sementes dispersadas e o local onde as sementes são depositadas.

Em conclusão, os resultados obtidos indicam que os padrões de deposição das sementes de Gomidesia e Marlierea testados podem levar a diferenças importantes relacionadas à sobrevivência de sementes e plântulas em seus primeiros meses de vida. A deposição de sementes isoladas, mais freqüentemente produzida pelas aves, propicia um balanço entre número de sementes dispersadas e número de plântulas estabelecidas mais favorável que o padrão agrupado, freqüentemente produzido pelos macacos. Caso aves e macacos não difiram em outros aspectos relacionados à eficiência da dispersão (por exemplo, quantidade de sementes dispersadas), este balanço mais favorável indica que as aves otimizam os esforços reprodutivos das plantas aqui pesquisadas. É importante notar, entretanto, que a magnitude das diferenças entre os dois padrões de deposição (e também sua direção no caso da sobrevivência de sementes e plântulas consideradas separadamente) varia interespecificamente.

Para avaliar adequadamente as possíveis conseqüências demográficas e pressões seletivas produzidas por aves e macacos sobre as plantas cujos frutos compartilham, faz-se necessário um estudo de longa duração que acompanhe a sobrevivência das plântulas e seu recrutamento às populações.

Agradecimentos - À Fundação Florestal do Estado de São Paulo por apoiar meu trabalho de longos anos no Parque Intervales, especialmente à diretora do Parque Intervales Jeannette V. Geenen que possibilitou o acesso às instalações da Base Saibadela. Sou grato também a Wesley R. Silva, L. Patrícia C. Morellato e Emerson M. Vieira pelas sugestões ao manuscrito. Este trabalho foi possível graças ao apoio da Fapesp (processos n. 95/9626-0 e 98/11185-0), International Foundation for Science (D/2953-1), Idea Wild e às facilidades oferecidas pelo Departamento de Botânica da Unesp, Rio Claro.

\section{Referências bibliográficas}

ALMEIDA-SCABBIA, R. 1996. Fitossociologia de um trecho de Mata Atlântica no sudeste do Brasil. Tese de mestrado, Universidade Estadual Paulista, Rio Claro.

BLATE, G.M., PEART, D.R. \& LEIGHTON, M. 1998. Postdispersal predation on isolated seeds: a comparative study of 40 tree species in a southeast Asian rainforest. Oikos 82:522-538.

BRIANI, D.C., VIEIRA, E.M. \& VIEIRA, M.V. 2001. Nesting and nesting sites of Brazilian forest rodents (Nectomys squamipes and Oryzomys intermedius) revealed by a spool-and-line device. Acta Theriologica 46:331-334.

CHAPMAN, C.A. 1989. Primate seed dispersal: the fate of dispersed seeds. Biotropica 21:148-154.

CLARK, C.J., POULSEN, J.R. \& PARKER, V.T. 2001. The role of arboreal seed dispersal groups on the seed rain of a lowland tropical forest. Biotropica 33:606-620.

FORGET, P.M. \& MILLERON, T. 1991. Evidence for secondary seed dispersal by rodents in Panama. Oecologia 87:596-599.

HAMMOND, D.S. 1995. Post-dispersal seed and seedling mortality of tropical dry forest trees after shifting agriculture. Journal of Tropical Ecology 11:295-313.

HERRERA, C.M. 1992. Historical effects and sorting processes as explanantions for contemporary ecological patterns: caracter sindromes in Mediterranean woody plants. American Naturalist 140:421-446.

HOWE, H.F. 1980. Monkey dispersal and waste of a neotropical fruit. Ecology 61:944-959.

HOWE, H.F. 1989. Scatter- and clump-dispersal and seedling demography: hypothesis and implications. Oecologia 79:417-426. 
HULME, P.E. \& HUNT, M.K. 1999. Rodent post-dispersal seed predation in deciduous woodland: predator response to absolute and relative abundance of prey. Journal of Animal Ecology 68:417-428.

IZAR, P. 1999. Aspectos de ecologia e comportamento de um grupo de macacos-prego (Cebus apella) em área de Mata Atlântica, São Paulo. Tese de doutorado, Universidade de São Paulo, São Paulo.

JANSON, C.H. 1992. Measuring evolutionary constraints: a markov model for phylogenetic transitions among seed dispersal syndromes. Evolution 46:136-158.

JOLY, A.C., LEITÃO FILHO, H.F. \& SILVA, S.M. 1991. Mata Atlântica. Editora Index Ltda. e Fundação SOS Mata Atlântica, São Paulo.

JORDANO, P. 1995. Angiosperm fleshy fruits and seed dispersers: a comparative analysis of adaptation and constraints in plant-animal interactions. American Naturalist 145:163-191.

JULLIOT, C. 1997. Impact of seed dispersal by howler monkeys Alouatta seniculus on the seedling population in the understorey of a tropical rain forest. Journal of Ecology 85:431-440.

KELRICK, M.I., MACMAHON, J.A., PARMENTER, R.R. \& SISSON, D.V. 1986. Native seed preferences of shrub-steppe rodents, birds and ants: the relationship of seed attributes and seed use. Oecologia 68:327-337.

LEVEY, D.J. 1987. Seed size and fruit-handling techniques of avian frugivores. American Naturalist 129:471-485.

LOISELLE, B.A. 1990. Seeds in droppings of tropical fruiteating birds: importance of considering seed composition. Oecologia 82:404-500.
NOTMAN, E., GORCHOV, D.L. \& CORNEJO, F. 1996. Effect of distance, aggregation, and habitat on levels of seed predation for two mammal-dispersed neotropical rain forest tree species. Oecologia 106:221-227.

PETRONI, L.M. 2000. Caracterização da área de uso e dieta do Mono Carvoeiro (Brachyteles arachnoides, Cebidae Primates), na Mata Atlântica, Serra de Paranapiacaba, SP. Tese de doutorado, Universidade de São Paulo, São Paulo.

PIZO, M.A. 2002. The seed dispersers and fruit syndromes of Myrtaceae in the Brazilian Atlantic forest. In Seed dispersal and frugivory: ecology, evolution and conservation (D.J. Levey, W.R. Silva \& M. Galetti, eds.). CABI Publishing, Wallingford, p.129-143.

PIZO, M.A. \& SIMÃO, I. 2001. Seed deposition patterns and the survival of seeds and seedlings of the palm Euterpe edulis. Acta Oecologica 22:229-233.

SCHUPP, E.W. 1993. Quantity, quality and the effectiveness of seed dispersal by animals. Vegetatio 107/108:15-29.

SMA (Secretaria de Estado do Meio Ambiente). 2001. Intervales. Secretaria de Estado do Meio Ambiente, São Paulo.

VAN DER PIJL, L. 1982. Principles of seed dispersal in higher plants. $3^{\text {rd }}$ ed. Springer-Velag, Berlin.

VIEIRA, E.M. 1999. Estudo comparativo da comunidade de pequenos mamíferos em duas áreas de Mata Atlântica situadas em diferentes altitudes no sudeste do Brasil. Tese de doutorado, Universidade Estadual de Campinas, Campinas.

WILLSON, M.F. \& WHELAN C.J. 1990. Variation in postdispersal survival of vertebrate-dispersed seeds: effects of density, habitat, location, season, and species. Oikos 57:191-198.

ZAR, J. H. 1984. Biostatistical analysis. Prentice-Hall, Londres. 
